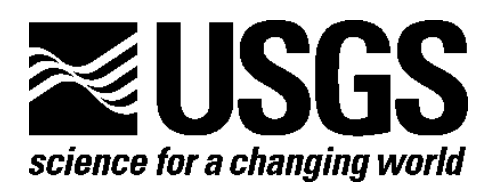

\title{
Prompt Assessment of Global Earthquakes for Response (PAGER): A System for Rapidly Determining the Impact of Earthquakes Worldwide
}

By Paul S. Earle, David J. Wald, Kishor S. Jaiswal, Trevor I. Allen, Michael G. Hearne, Kristin D. Marano, Alicia J. Hotovec, and Jeremy M. Fee

Open-File Report 2009-1131 


\section{U.S. Department of the Interior \\ KEN SALAZAR, Secretary}

\section{U.S. Geological Survey \\ Suzette M. Kimball, Acting Director}

U.S. Geological Survey, Reston, Virginia 2009

For product and ordering information:

World Wide Web: http://www.usgs.gov/pubprod

Telephone: 1-888-ASK-USGS

For more information on the USGS-the Federal source for science about the Earth,

its natural and living resources, natural hazards, and the environment:

World Wide Web: http://www.usgs.gov

Telephone: 1-888-ASK-USGS

Suggested citation:

Earle, P.S., Wald, D.J., Jaiswal, K.S., Allen, T.I., Hearne, M.G, Marano, K.D., Hotovec, A.J., and Fee, J.M., 2009, Prompt Assessment of Global Earthquakes for Response (PAGER)_A system for rapidly determining the impact of earthquakes worldwide: U.S. Geological Survey Open-File Report 2009-1131, 15 p.

Any use of trade, product, or firm names is for descriptive purposes only and does not imply endorsement by the U.S. Government.

Although this report is in the public domain, permission must be secured from the individual copyright owners to reproduce any copyrighted material contained within this report. 


\section{Contents}

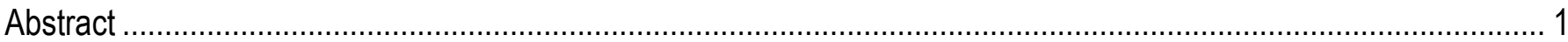

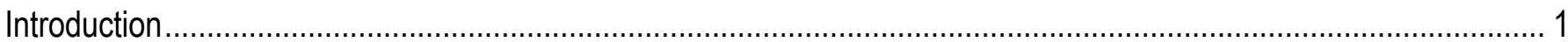

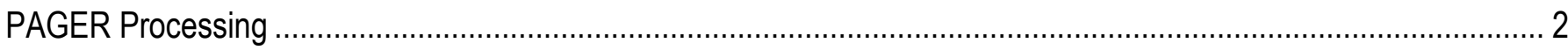

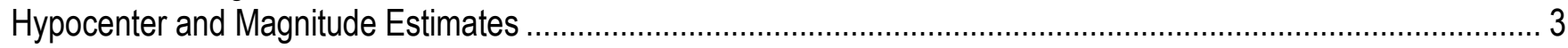

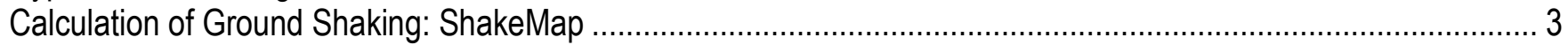

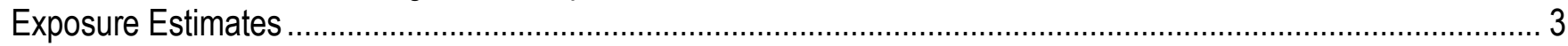

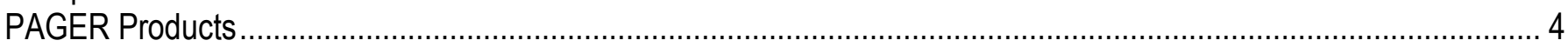

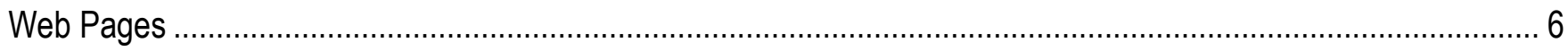

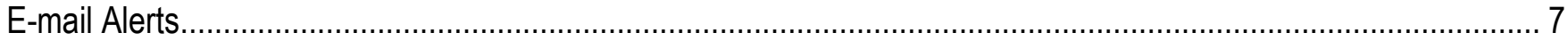

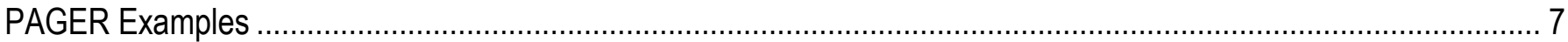

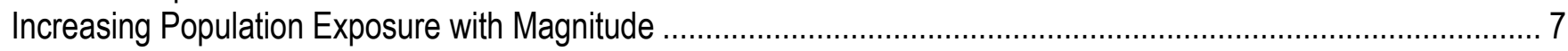

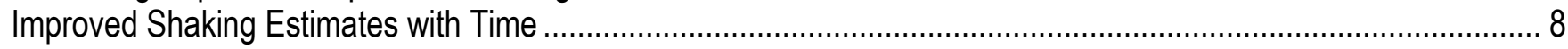

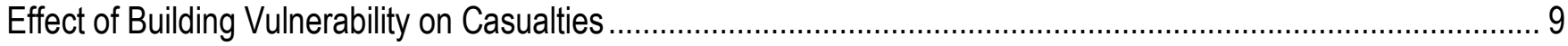

PAGER Future

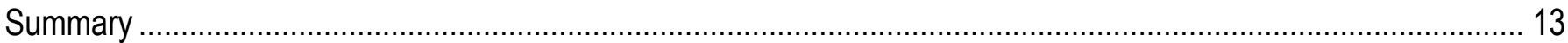

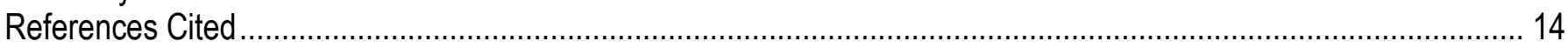

\section{Figures}

Figure 1. An example of a onePAGER report for the 12 May 2008 Wenchuan, China, earthquake...................... 5

Figure 2. Maps of population and shaking distribution for the 12 May 2008 Wenchuan, China, earthquake............ 8

Figure 3. Evolution of PAGER results for the 12 May 2008 Wenchuan, China, earthquake ................................ 10

Figure 4. Shaking distribution for the 1995 Northridge, California, and 2005 Pakistan earthquake ..................... 11 


\title{
Prompt Assessment of Global Earthquakes for Response (PAGER): A System for Rapidly Determining the Impact of Earthquakes Worldwide
}

By Paul S. Earle, David J. Wald, Kishor S. Jaiswal, Trevor I. Allen, Michael G. Hearne, Kristin D. Marano, Alicia J. Hotovec, and Jeremy M. Fee

\begin{abstract}
Within minutes of a significant earthquake anywhere on the globe, the U.S. Geological Survey (USGS) Prompt Assessment of Global Earthquakes for Response (PAGER) system assesses its potential societal impact. PAGER automatically estimates the number of people exposed to severe ground shaking and the shaking intensity at affected cities. Accompanying maps of the epicentral region show the population distribution and estimated ground-shaking intensity. A regionally specific comment describes the inferred vulnerability of the regional building inventory and, when available, lists recent nearby earthquakes and their effects. PAGER's results are posted on the USGS Earthquake Program Web site (http://earthquake.usgs.gov/), consolidated in a concise one-page report, and sent in near realtime to emergency responders, government agencies, and the media. Both rapid and accurate results are obtained through manual and automatic updates of PAGER's content in the hours following significant earthquakes. These updates incorporate the most recent estimates of earthquake location, magnitude, faulting geometry, and first-hand accounts of shaking. PAGER relies on a rich set of earthquake analysis and assessment tools operated by the USGS and contributing Advanced National Seismic System (ANSS) regional networks. A focused research effort is underway to extend PAGER's near realtime capabilities beyond population exposure to quantitative estimates of fatalities, injuries, and displaced population.
\end{abstract}

\section{Introduction}

It can take days to determine the scope of an earthquake disaster. Six hours after the 12 May 2008 Wenchuan, China, earthquake, major news agencies were reporting 6 deaths. The number of reported fatalities steadily grew over the next 10 days before approaching nearly 70,000 killed and 20,000 missing. Following, the 27 May 2006 Java earthquake, it took close to three days for the reported death count to near the final estimate of almost 6,000. Relying solely on such reports for earthquake response would delay the humanitarian response, prolong suffering, and potentially increase the death toll. To address this delay the USGS National Earthquake Information Center (NEIC) developed the Prompt Assessment of Global Earthquakes for Response (PAGER) system (Wald and others, 2008a).

PAGER is an automated system that immediately estimates an earthquake's impact on humans for events anywhere worldwide. The system estimates the number of people exposed to potentially damaging shaking and distributes alerts and associated maps to users via wireless devices, e-mail, and the Internet. PAGER's rapid estimates of an earthquake's impact, and its supporting products, inform decisions by governments, insurance agencies, and relief organizations to release aid funds, prioritize regions for closer reconnaissance, and mobilize rescue teams. 
The USGS NEIC is a fitting host for PAGER. The NEIC 24/7 onsite staff reports over 30,000 earthquakes a year and often detects damaging earthquakes well before eyewitness reports are available. The NEIC has produced authoritative global earthquake locations and magnitudes for over 30 years and is the only U.S. seismic monitoring system Federally mandated to provide earthquake information worldwide. As such, NEIC has direct contact with the White House, U.S. Agency for International Development, the State Department, numerous foreign governments, and major media outlets. In total, over 143,000 individuals and organizations currently receive USGS/ANSS earthquake alerts (Wald and others, 2008). Additionally, systems that generate fundamental input for loss estimation are developed and operated at the NEIC, including ShakeMap (Wald and others, 1999b; Wald and others, 2005), which calculates maps of ground shaking, Community Internet Intensity Maps (known as "Did You Feel It?"; Wald and others, 1999a), which gathers public reports of near-source shaking intensity, and systems that estimate the faulting style and extent.

Earthquake impact and loss estimation have many uses beyond rapid situational awareness. Scenario loss estimates calculated for potential future earthquake disasters, such as a reoccurrence of the 1906 San Francisco earthquake (Kircher and others, 2006), can be use to educate policy makers, motivate mitigation efforts, increase public awareness, and train emergency response personal. Additionally, insurance companies rely on loss estimation to evaluate portfolio risk, set insurance rates, and release catastrophe bonds. Generally, software used by insurance companies is proprietary and focuses on limited regions within developed nations and on portfolios of well-built engineered structures.

The majority of loss estimation methodologies and software are designed for non-real-time applications targeting specific regions; however, there are a few operational systems, in addition to PAGER, that address the challenge of rapid impact estimation for global earthquakes. The Joint Research Centre - Institute for the Protection and Security of the Citizen (JRC-IPSC) operates the Global Disaster Alert and Coordination System (GDACS), a content rich Web site and alert service that "provides near real-time alerts about natural disasters around the world and tools to facilitate response coordination" (http://www.gdacs.org/). The World Agency of Planetary Monitoring and Earthquake Risk Reduction (WAPMERR), in collaboration with the Swiss Seismological Service, operates QUAKELOSS, a proprietary system that produces estimates of fatalities and injuries and maps of the affected settlements. WAPMERR produces earthquake loss estimates in near real-time, generally within 40 minutes of an earthquake's occurrence (Wyss, 2004). QUAKELOSS primarily relies on NEIC's earthquake information to trigger its operation. QUAKELOSS is also operated by the Extreme Situations Research Center (Shakhramanian and others, 2000) who originally developed the proprietary software and databases, although their near real-time results are not publicly available.

This paper briefly outlines the scientific and technical details of the PAGER system and focuses on interpretation of PAGER output. The PAGER Processing section describes how the shaking and exposure estimates are generated. The PAGER Products section describes PAGER's alerts and supporting materials. The PAGER Examples section provides several example alerts and is a useful guide for interpreting PAGER results. The PAGER Future section briefly describes the ongoing work to extend PAGER's population exposure estimates to include quantitative loss estimates.

\section{PAGER Processing}

The basic process PAGER uses to estimate the population and cities exposed to shaking is straightforward. However, the generation of the individual components and the operations of a robust real-time system are complex. The basic automated process begins with the near real-time earthquake parameters of hypocenter and magnitude calculated by the NEIC and contributing ANSS regional seismic networks (Sipkin and others, 2006). Using these parameters, maps of ground shaking are 
produced by the USGS ShakeMap system. The shaking maps are merged with population and geographic databases to produce estimates of the number of people exposed to different levels of shaking and the shaking intensities at selected cities.

\section{Hypocenter and Magnitude Estimates}

In densely instrumented regions like California, location and magnitude estimates are produced within several minutes of the earthquake's occurrence, whereas, in sparsely instrumented regions of the world, estimates are generally available within 20 minutes. Magnitude and location estimates improve with time as more data are received and more sophisticated processing is applied. These updates can be significant and necessitate the production of updated PAGER alerts if the updated solution significantly differs from the preliminary alerts.

\section{Calculation of Ground Shaking: ShakeMap}

Estimates of ground shaking are fundamentally different from magnitude and epicenter. While an earthquake has one magnitude and one epicenter, it produces a range of ground shaking throughout the affected region. The maps of ground shaking used by PAGER are produced by the USGS ShakeMap system (Wald and others, 1999b; Wald and others, 2005). ShakeMap produces maps for several groundmotion measurement types, including peak ground acceleration, peak ground velocity, peak spectral response, and Instrumental Intensity.

PAGER uses ShakeMap's estimates of Instrumental Intensity for its alerts because they are an intuitive measure of potential impact. ShakeMap's intensity estimates are calibrated to the Modified Mercalli Intensity (MMI) scale (for example, Dewey and others, 1995) that describes the severity of an earthquake in terms of its effect on humans and structures. Traditionally, MMI is stated in integer values and expressed using Roman numerals.

The severity of ground shaking generally decreases with distance from the ruptured fault; however, other factors contribute to local variations in ground shaking, such as amplification due to soft soil conditions. Preferably, ShakeMap uses geologic data to predict site amplification but, in regions where no such data are available, ShakeMap approximates site amplification using an empirical relationship based on topographic slope (Wald and Allen, 2007).

The most accurate ShakeMaps are those constrained by measurements from strong-motion seismometers in the region surrounding the ruptured fault. These instrumental measurements are generally only available in the most hazardous, populated regions within developed countries. Unfortunately, there are insufficient seismic stations to generate instrumentally constrained ShakeMaps for most deadly earthquakes around the world. For these earthquakes, ShakeMaps are constrained using empirical ground motion prediction equations based on magnitude, site amplification, and distance to to the fault, as well as any observations reported by people in the shaken region using the USGS "Did You Feel It" system (Wald and others, 1999a). The "Did You Feel It" (DYFI) system collects first-person observations from the areas affected by shaking using publicly accessible Internet questionnaires (http://earthquake.usgs.gov/dyfi/). When available, the answers to the questions are automatically converted to estimates of shaking intensity and are used to constrain the ShakeMap.

\section{Exposure Estimates}

PAGER routinely calculates two types of exposure estimates: (1) the total number of people exposed to shaking at different intensities and (2) the intensities at selected settlements. PAGER estimates the population exposed to different shaking intensities using Oakridge National Lab's 
LandScan global population database (Bhaduri and others, 2002). The LandScan population is distributed on a 30x30 second latitude/longitude grid, or about $1 \mathrm{~km}^{2}$ near the equator

(http://www.ornl.gov/sci/landscan/). PAGER produces a population exposure table by summing all the population cells at given intensity values as estimated by ShakeMap. This table is currently PAGER's best indication of the possible impact of an earthquake.

The shaking intensity and population of selected settlements are obtained using the GeoNames geographical database. The GeoNames database (http://www.geonames.org/) contains the location and population of 2.2 million places compiled from numerous sources. GeoNames is freely available and continually updated through user input. The shaking at a particular settlement is set to the value at its designated GeoNames location. For, large cities with significant geographic extent the intensity is likely to vary across city limits but a point estimate should be adequate for all but the largest cities. Intensity estimates for affected settlements are useful for prioritizing areas for closer reconnaissance.

\section{PAGER Products}

PAGER's estimates of people and settlements exposed to shaking are incorporated into a suite of products available through e-mail and Web pages. PAGER products are generated for all earthquakes magnitude 5.5 and greater globally and down to magnitudes of about 3.5 to 4.5 within the contiguous United States, Alaska, and Hawaii. Alerts are generally distributed within 15 minutes after an earthquake in the United States and within 25 minutes for earthquakes outside the United States.

PAGER's signature product is a concise one-page summary report called the "onePAGER." An understanding of the maps and tables in this report provides users with the background necessary to quickly assess the possible impact of an earthquake. OnePAGER reports are in Adobe Portable Document Format (PDF), distributed by e-mail and available on the Internet. Figure 1 shows an example of a onePAGER report for the 12 May 2008 M7.9 Wenchuan, China, earthquake.

The basic earthquake parameters are printed at the top of the onePAGER report and include the origin time, magnitude, hypocenter, and the name of the region where the earthquake took place. For large earthquakes, the location and magnitude are updated as seismic data are collected and analyzed. These updates occur in the hours and days following the earthquake. However, significant changes after the first few hours are infrequent.

To the right of the earthquake parameters on the onePAGER report are the version number of the PAGER alert and the time it was created. New versions are generated when the location or magnitude is updated or when ShakeMaps are improved by the inclusion of localized measurements of ground shaking or data that constrain the length and orientation of the fault rupture. Recipients of PAGER alerts should check the Internet for updates periodically because generally only the first version of the alert for each earthquake is distributed via e-mail, unless very significant changes occur. 
M 7.9, EASTERN SICHUAN, CHINA

Origin Time: Mon 2008-05-12 06:28:00 UTC

Location: $31.10^{\circ} \mathrm{N} 103.28^{\circ} \mathrm{E}$ Depth: $10 \mathrm{~km}$

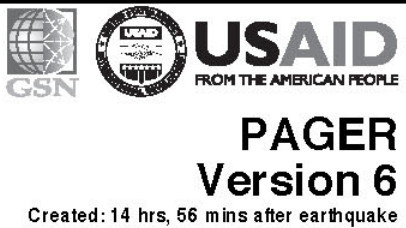

Estimated Population Exposed to Earthquake Shaking

\begin{tabular}{|c|c|c|c|c|c|c|c|c|c|c|}
\hline \multicolumn{2}{|c|}{$\begin{array}{l}\text { ESTMATED POPULATION } \\
\text { EXPOSURE }(k=x 1000)\end{array}$} & $--^{*}$ & $--^{*}$ & $181,513 \mathrm{k}^{*}$ & $89,747 \mathrm{k}$ & $15,409 \mathrm{~K}$ & $12,351 \mathrm{k}$ & $3,962 \mathrm{k}$ & $668 k$ & $606 \mathrm{k}$ \\
\hline \multicolumn{2}{|c|}{$\begin{array}{l}\text { ESTMATED MODIFIED } \\
\text { MERCALLI INTENSITY }\end{array}$} & I & II-III & IV & v & VI & VII & VIII & IX & $\mathrm{X+}$ \\
\hline \multicolumn{2}{|c|}{ PERCEIVED SHAKING } & Not felt & Weak & Light & Moderate & Strong & Very strong & Severe & Violent & Extreme \\
\hline \multirow{2}{*}{$\begin{array}{l}\text { POTENTIAL } \\
\text { DAMAGE }\end{array}$} & $\begin{array}{l}\text { Resistant } \\
\text { Structures }\end{array}$ & none & none & none & V. Light & Light & Moderate & Moderate/Heavy & Heavy & V. Heavy \\
\hline & $\begin{array}{l}\text { Vulnerable } \\
\text { Structures }\end{array}$ & none & none & none & Light & Moderate & Moderate/Heavy & Heavy & V. Heavy & V. Heavy \\
\hline
\end{tabular}

"E stim ated exposure only includes population within the map area.

Population Exposure population per $\sim 1$ sq. km from Landscan 2005 Selected City Exposure

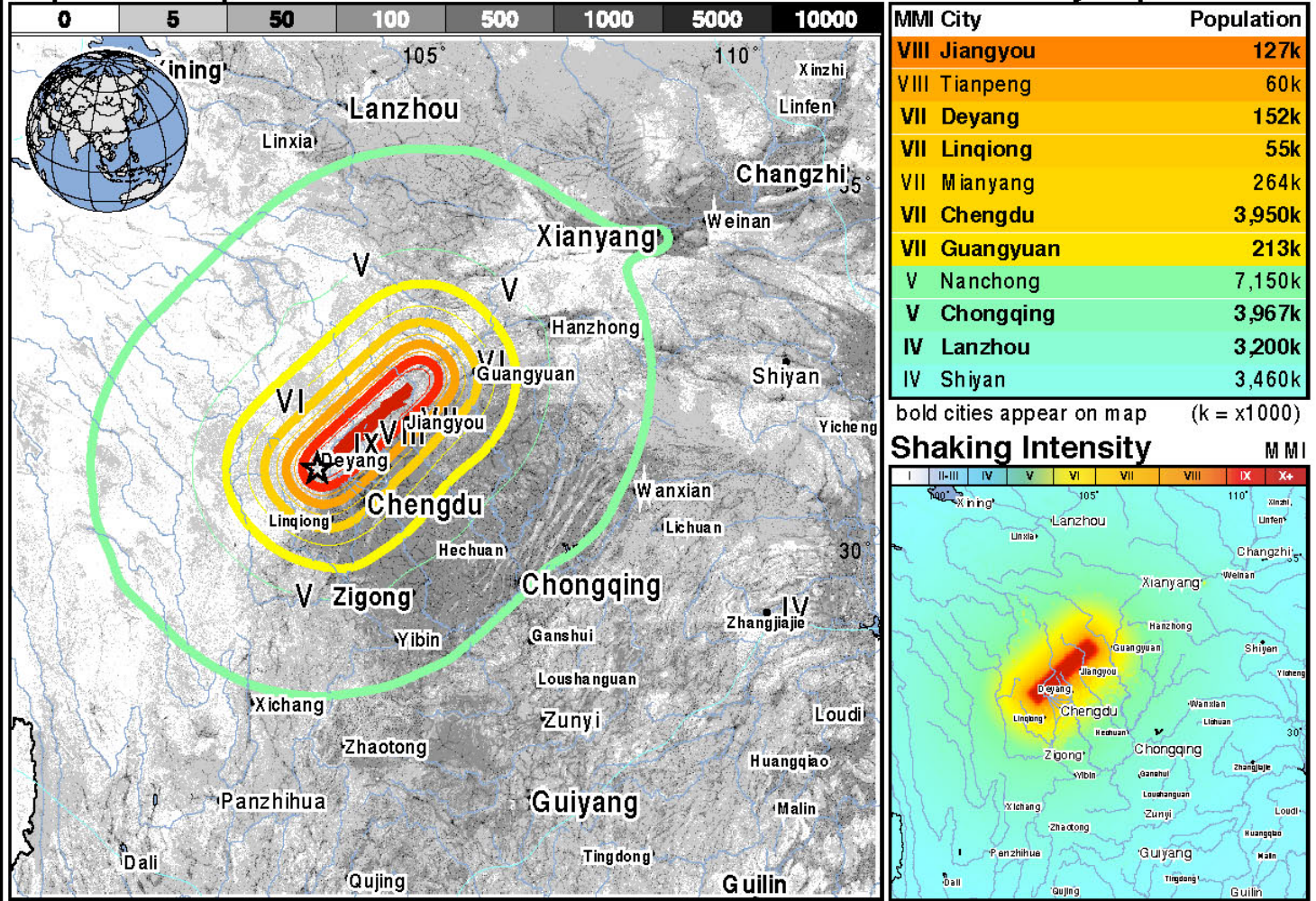

O verall, structures in this region are vulnerable to earthquake shaking, though some re sistant structures exist. $A$ magnitude 6.4 earthquake struck the Sichuan, China region on August 23, 1976 (UTC), with estimated population exposures of 1,500 at intensity IX or greater and 5,700 at intensity VIII, resulting in 41 deaths. Additionally, a magnitude 7.3 struck this region in 1933 killing 6,800 people. Recent earthquakes in this area have also trigge red landslide hazards that have contributed to losses. U sers should consider the preliminary nature of this information and check for updates as additional data becomes available.

Figure 1. An example of a onePAGER report for the 12 May 2008 Wenchuan, China, earthquake. The onePAGER report contains a concise summary of the main PAGER results. 
PAGER's most indicative information about the potential impact of an earthquake is contained in the table that shows the population exposed to different estimated intensity levels. The table also provides a rough guide to possible damage at different intensity levels for resistant and vulnerable structures. The damage caused by an earthquake greatly depends on the construction of the buildings shaken. Given similar population exposures at high intensities, earthquake fatalities in the world's most vulnerable regions can result in 4,500 times more deaths than in the most resistant regions.

A smaller table lists the population and estimated intensity for up to eleven settlements and cities that fall within the map boundaries. The table preferentially contains country capitals and the six settlements with the highest estimated intensity. The remaining settlements listed are the ones within the map bounds with the highest population. The table and PAGER maps do not include settlements with fewer than 1,000 people or without population data in the GeoNames database. The listed cities are often part of a larger, connected urban area, so users should consider that the exposure reported for a city will potentially be considerably less than that for the entire urban area.

A gray-scale map with superimposed color contours shows the population and estimated intensity contours. The regions of integer intensity values are separated by the thick contour lines and labeled with Roman numerals; contours are shown as dashed lines over water. The population is shown in gray scale with the darkest values saturating at 1,000 people per $30 \times 30$ second cell (about $1 \mathrm{~km}^{2}$ near the equator). The epicenter is shown as a black star and marks the place above where the earthquake rupture began. A smaller map shows shaking intensity as a continuous color gradient, resembling ShakeMap.

To help the user interpret the possible impact of the alerted earthquake, a regionally specific comment is provided below the maps. The comment describes the overall vulnerability of the buildings in the area and gives examples of population exposures and fatality totals for previous, nearby earthquakes. The building vulnerability is generally obtained from a country-based building inventory specifically compiled for PAGER (Jaiswal and Wald, 2008). The quality of these surveys and consequently our vulnerability estimates vary on a country-by-country basis. The initial comment is generated automatically but is sometimes manually revised.

The population exposure estimates and resulting fatalities from previous nearby earthquakes, described in the comment, serve as a rough guide for the possible impact of an alerted earthquake. Similar exposure estimates will likely produce similar damage. However, the user should expect considerable variation, especially for low-fatality earthquakes, since these deaths are often the result of isolated collapses of anomalously weak buildings. Additionally, the quality of the exposure estimates and reported historic fatalities vary for different earthquakes.

The population exposure estimates for previous earthquakes are derived from the USGS Atlas of ShakeMaps (Allen and others, 2008) and the Landscan population database, adjusted for time-dependent population changes. Because both the population data and seismological parameters decrease in quality for older events, only earthquakes since 1973 are contained in the comments.

\section{Web Pages}

The PAGER Web pages (http://earthquake.usgs.gov/eqcenter/pager/) contain an expanded version of the content contained in the onePAGER. The homepage contains an interactive Google Maps view of the events occurring within the last week. Supporting pages contain background information and links to published reports and PAGER databases. A searchable archive contains the results for all significant events PAGER has processed since its public release in September 2007. The download section provides access to event specific content including the onePAGER reports and associated maps. The ground shaking estimates used by PAGER are available for download in several formats (for 
example, shapefile, KML, ASCII) from the ShakeMap Web pages

(http://earthquake.usgs.gov/eqcenter/shakemap/).

\section{E-mail Alerts}

E-mail PAGER alerts are distributed in "short" and "long" text formats. The short format is suitable for reading on a cell phone or mobile device and contains the earthquake location, depth, region name, and number of people exposed to the four highest intensity levels. The long format e-mail contains the same information plus the regionally-specific comment, intensity estimates at selected cities, and, optionally, the onePAGER report as an attached Portable Document Format (PDF) file.

Recipients of PAGER e-mail alerts specify an intensity and magnitude threshold. A user receives an alert if his or her intensity or magnitude threshold is exceeded. Intensity-based alerts have the advantage of reducing the number of alerts users receive because large earthquakes in unpopulated regions will not trigger e-mails. For example, a user with a PAGER threshold of intensity XII and magnitude 7.5 will receive about 120 alerts per year. With this threshold the user will receive alerts for all but about 5 percent of the earthquakes killing 20 or more people. To receive this level of success from a magnitude-only alert, the user's threshold would have to be set to magnitudes greater than about 5.5. With this threshold, he or she would receive over 350 alerts per year.

Even with intensity-based alerts, some deadly events will be missed. Even moderate shaking experienced over a broad area will occasionally collapse a few extremely weak or previously compromised buildings. This situation, while tragic, rarely results in a large-scale disaster that requires external assistance.

\section{PAGER Examples}

Examination of PAGER output from previous events provides a foundation for understanding future alerts. In this section, we show several examples that illustrate (1) the increase in population exposure to severe shaking with magnitude, (2) how PAGER exposure estimates improve with time, and (3) the strong effect of building vulnerability on earthquake casualties.

\section{Increasing Population Exposure with Magnitude}

It is intuitive that larger magnitude earthquakes cause more damage than smaller ones but the reason is not simply an increase in shaking intensity at higher magnitudes. In addition to producing higher-amplitude shaking, larger earthquakes also shake a greater area. Ground-shaking amplitude depends on how far away a site is from the fault rupture, not how far away the site is from the rupture's initiation point (hypocenter). The length of rupture increases rapidly with magnitude, thus extending the area exposed to the highest levels of shaking produced by the earthquake. For a magnitude 6.0 earthquake, the rupture length on a strike slip-fault such as the San Andreas will typically be about 15 $\mathrm{km}$, for magnitude 7.0 the length increases to about $60 \mathrm{~km}$, and a magnitude 8.0 event will generally rupture a $250-\mathrm{km}$ fault (Wells and Coppersmith, 1994). Therefore, the region of strongest shaking produced by a magnitude 6.0 earthquake will extend for about $15 \mathrm{~km}$, whereas the highest shaking levels produced by a magnitude 8.0 will extend for $250 \mathrm{~km}$

Figure 2 illustrates how the shaking intensity and area exposed to severe shaking increases with magnitude. It shows ShakeMaps and PAGER results for the M7.9 Wenchuan, China, earthquake and a M6.0 aftershock that occurred on the same day. The M7.9 mainshock ruptured a fault about $300 \mathrm{~km}$ 
long and exposed an estimated 1.2 million people to the two highest intensities generated by the earthquake (IX and X). The M6.0 aftershock ruptured a fault about $10 \mathrm{~km}$ long and exposed an estimated 0.6 million people to the two highest intensities produced by the earthquake (VI and VIII).

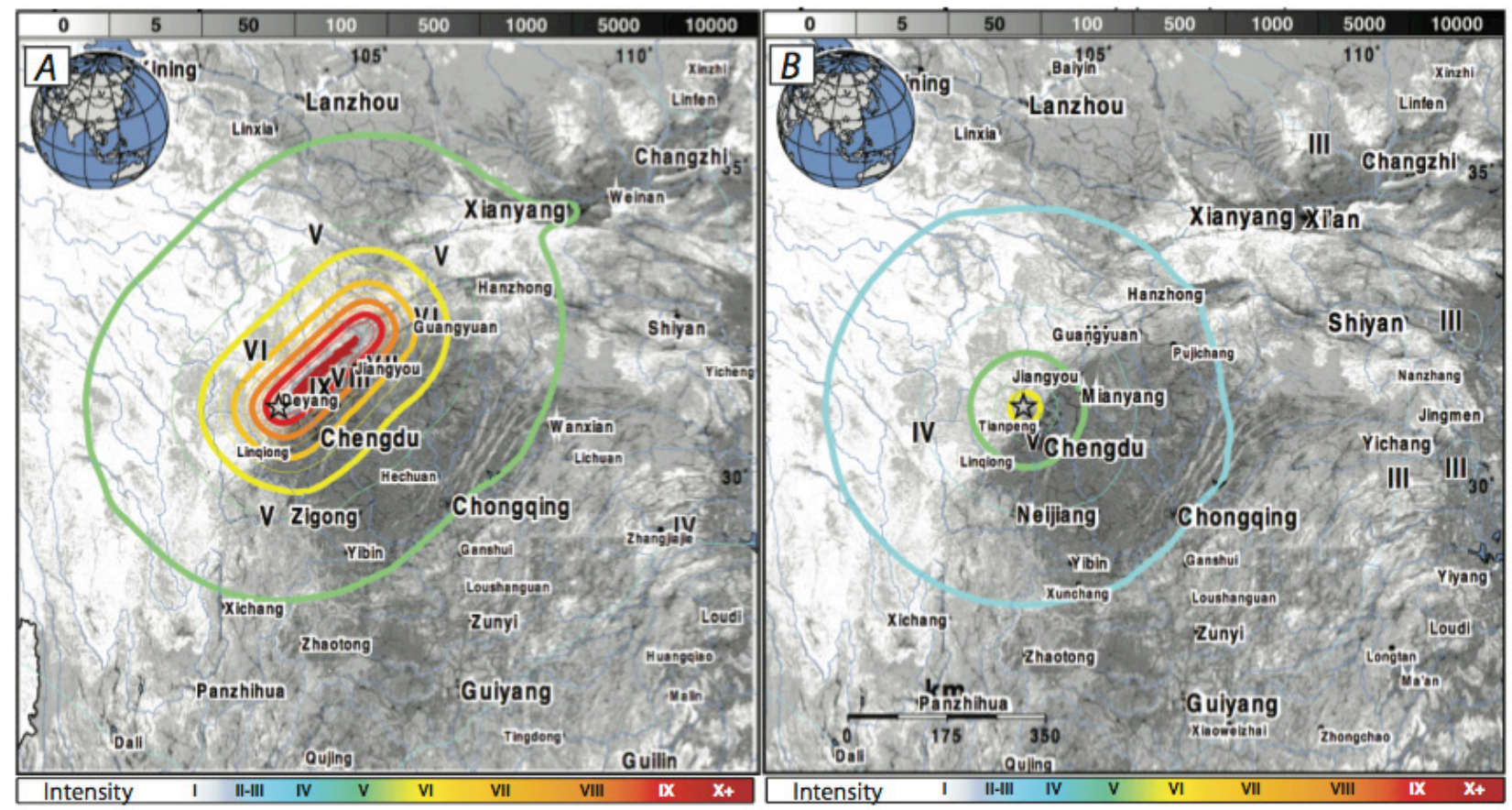

Figure 2. Maps of population and shaking distribution for the12 May 2008 Wenchuan, China, earthquake and an aftershock. $A$, M 7.9 mainshock $B$, M 6.0 aftershock. The grayscale background shows the population per approx. $1 \mathrm{~km}^{2}$ and the color contours indicate the intensity. Both the maximum intensity and the area exposed to the maximum intensity increases with earthquake magnitude. The shaking contours for the magnitude 6.0 aftershock are nearly concentric circles due to its small rupture area, whereas the oval shaking contours for the main shock are a consequence of its $300-\mathrm{km}$ rupture..

\section{Improved Shaking Estimates with Time}

The accuracy of PAGER's exposure results improves with time as more data become available to better estimate shaking intensity. To keep PAGER results both prompt and accurate, several alert versions are produced in the hours following significant earthquakes. For earthquakes smaller than about magnitude 6.5, significant changes in estimated population exposure rarely occur after the first few hours. For larger events with complex ruptures, it is usually clear from the first PAGER alert if an event is devastating, but it can take several hours to better understand the geographic extent of the strongest shaking. Numerous PAGER versions are posted to the Internet for the largest earthquakes, but only versions that significantly change the overall estimated exposure of an earthquake are redistributed via e-mail. The PAGER Web site should be checked periodically for the most recent maps and exposure estimates in the hours following a significant earthquake.

Figure 3 shows the evolution of PAGER's exposure estimates following the 12 May 2008 Wenchuan, China, earthquake. Eleven PAGER alert versions were produced for this earthquake, most of which were triggered automatically by small improvements to the location and magnitude. The three alert versions in figure 3 show the most significant changes in estimated shaking. The largest changes in 
PAGER exposure estimates primarily resulted from improved knowledge of the orientation and extent of the rupture.

The first PAGER exposure estimates for the Wenchuan earthquake were automatically generated and distributed 31 minutes after its occurrence (fig. $3 A$ ). Version 1 predicted 1.2 million people were exposed to intensity VIII or greater shaking. An exposure level this high, in a region with vulnerable infrastructure, is a clear indication of a disaster.

For all earthquakes, the initial ShakeMap intensity estimates contain no information about the fault orientation. Thus, ShakeMap predicts the strongest intensities near the epicenter. This "pointsource approximation" produces bulls-eye contours seen in figure $3 \mathrm{~A}$. The deviation of the contours from concentric circles results from different levels of shaking amplification resulting from changes in near-surface geology inferred using topographic slope.

Figure $3 B$ shows the third PAGER alert generated for the Wenchuan earthquake. Produced about 2 hours after the earthquake, it was the first version to incorporate an estimate of the rupture length and orientation. We inferred that the rupture propagated from the hypocenter to the northeast based on aftershocks, fault length vs. magnitude relations, and regional topography. The use of an extended linear fault for estimating shaking produces shaking contours of concentric ovals. The estimated population exposure to the highest intensities did not significantly change from PAGER's first estimate, but this version provided a better estimate of the geographical extent of the highest shaking levels.

Figure $3 C$ shows the sixth PAGER alert. Created about 14 hours after the event, this version contained the last significant change in PAGER's population exposure estimates. For this version, the estimated rupture width as well as its length was included and its length was extended further to the northeast primarily based on seismic waveform modeling of the rupture's extent. This more accurate representation of the earthquake's rupture increased PAGER's exposure estimate to about 5.2 million people exposed to intensity VIII or greater (about 4.3 times our original estimate).

\section{Effect of Building Vulnerability on Casualties}

The impact of an earthquake greatly depends on the vulnerability of the shaken buildings. Regions with highly vulnerable structures have fatality ratios many times greater than regions with earthquake resistant structures. Figure 4 shows the population exposure estimates for the 1995 Northridge, California, and the 2005 Pakistan earthquakes. The Northridge earthquake exposed 2.1 million people to severe (intensity VIII) or greater shaking and caused 33 deaths (Peek-Asa and others, 1998), and the Pakistan earthquake exposed about 1 million people to severe or greater shaking and caused over 87,000 deaths. The number of people killed in the Pakistan earthquake was nearly 2,500 times the number killed in the Northridge earthquake yet there were half the number of people exposed to the highest intensities. This enormous increase in fatalities primarily results from the collapse of highly vulnerable structures in Pakistan and the lack of collapse of the predominately shaking-resistant structures in Southern California. 


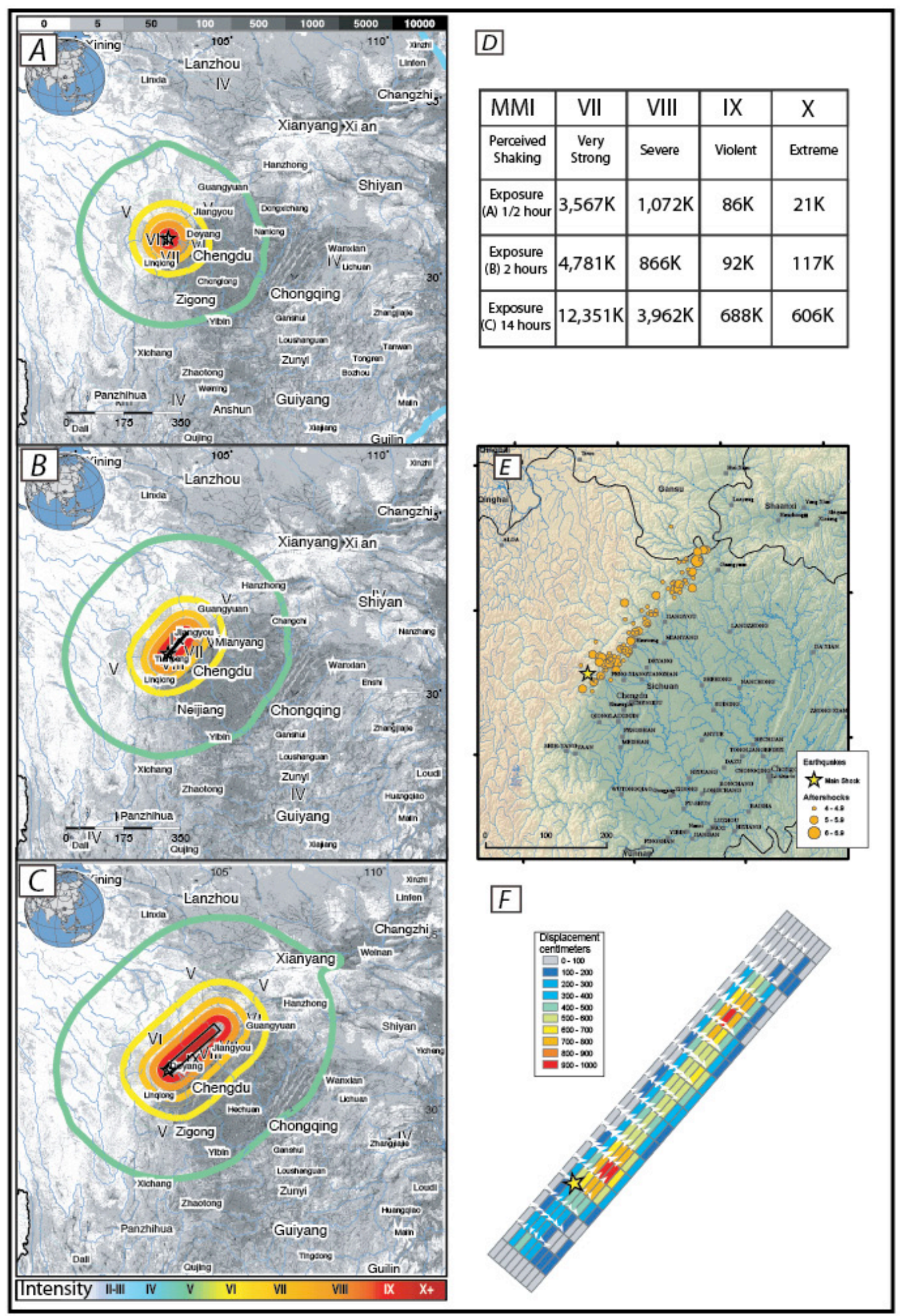

Figure 3. Evolution of PAGER results for the 12 May 2008, Wenchuan, China, earthquake. $A, B, C$ Color MMl contours plotted over grayscale population per approx. $1 \mathrm{~km}^{2}$ for PAGER alerts released 30 minutes, 2 hours, and 14 hours after the event, respectively. $D$, Estimated population exposure for the three alerts. $E$, Aftershocks recorded in the days following the earthquake. $F$, Finite-fault model used to estimate fault dimensions. 
PAGER reports the population exposed to different levels of shaking intensity, but the comparison of the Pakistan and Northridge earthquakes clearly demonstrates that an understanding of building vulnerability is needed to rapidly gauge the societal impact of an earthquake. As mentioned in the onePAGER description, PAGER provides a rough guide to the potential damage for resistant and vulnerable structures in the population exposure table. When available, population exposure estimates and reported fatalities for previous nearby earthquakes are provided in the comment. The likely impact of a recently reported earthquake can be gauged by comparing its exposure estimates to exposure values and reported deaths from previous nearby earthquakes

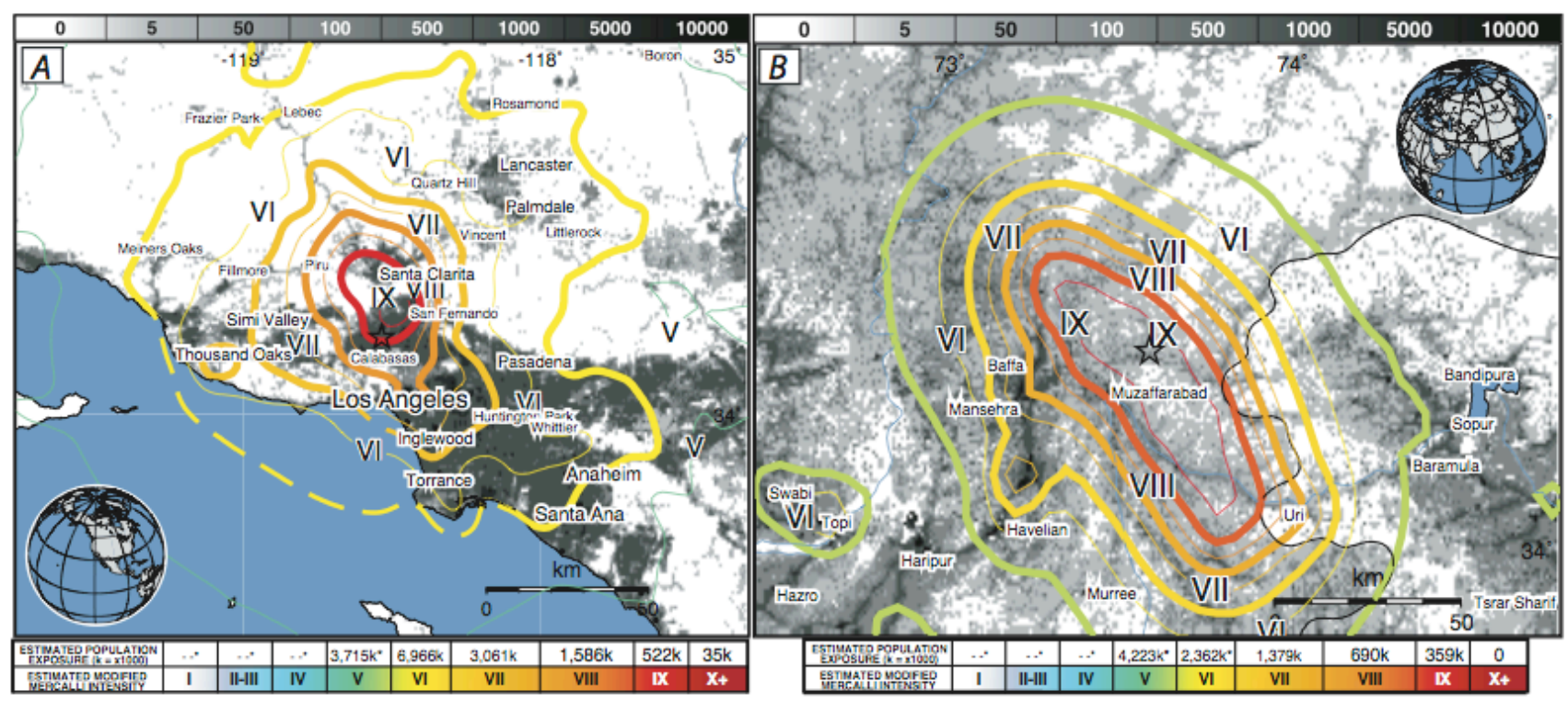

Figure 4. Comparison of the shaking distribution and population distribution for, $A$, the 1995 Northridge, California and, $B$, the 2005, Pakistan earthquake. The grayscale shows the population per approx. $1 \mathrm{~km}^{2}$ and the color contours indicate the intensity. The Northridge earthquake had twice the number of people exposed to Intensity VIII and greater than did the Pakistan earthquake, yet the Pakistan earthquake killed 87,000 people and the Northridge earthquake killed 33.

\section{PAGER Future}

PAGER currently reports the population exposed to different levels of shaking intensity, which is a useful indicator of an earthquake's potential impact. However, estimates of the number of people killed, injured, and displaced would provide more actionable information for emergency response. To provide this information, a significant effort is underway to develop earthquake loss models and collect the required datasets on a global scale.

The majority of earthquake loss estimation and risk assessment tools are for non-response purposes and focus on insured structures that are predominately well engineered and in developed countries. Most existing methodologies require detailed building inventory databases that are often proprietary and do not exist for most of the globe. To account for variable knowledge of regional infrastructure, PAGER will use a suite of three coordinated non-proprietary loss models that together are applicable to the entire globe. The three loss models in development are empirical (Jaiswal and others, in prep), semi-empirical (Jaiswal and others, 2008), and mostly analytical (Porter, in press). Employing three different models allows PAGER the flexibility to use more detailed inventory and 
engineering results in regions were these data are available but still to calculate loss estimates in regions where little is known about the distribution and vulnerability of the built infrastructure.

The empirical method uses reported losses from previous earthquakes to develop fatality-ratio functions (regional relations between ground-shaking intensity and fatalities). Following future earthquakes, these fatality-ratio functions will be combined with estimates of the population exposure at different intensity levels to provide fatality estimates. The methodology is most robust in regions that have experienced several large historic earthquakes and have well-documented fatality data. It is applicable to any regionalization with sufficient a priori constraints. PAGER's initial empirical models primarily use a country-based regionalization. Countries lacking historical data are assigned fatalityratio functions derived for countries with similarly built environments.

The semi-empirical and analytical loss models rely on a country-based building inventory (Jaiswal and Wald, 2008) and building vulnerabilities developed for use by PAGER. The key distinction between the semi-empirical and analytical methods is that the semi-empirical method uses intensity-based, collapse-probability functions primarily derived from expert opinion while the analytical method uses physics- and engineering-based collapse-probability functions obtained using spectral response and the capacity-spectrum approach (for example, Lin and Chang, 2003).

The empirical model does not require knowledge of the building inventory and therefore it cannot be employed directly for impact assessments beyond fatalities - the data used in its calibration. Alternatively, both the semi-empirical and analytical approaches require at least basic building inventories but provide estimates of the number of structural collapses allowing for the computation of other losses, including injuries, homelessness, and financial impact.

PAGER's loss models predict the number of deaths resulting from structural collapse. However, building collapse from shaking is not the sole contributor to earthquake loss; secondary effects such as landslides, liquefaction, fire, and tsunami have historically accounted for about 20 percent of earthquake related losses (Marano and others, in press). We are investigating methods to predict the likelihood and spatial distribution of liquefaction and landslides (Godt and others, 2008). Loss estimation from tsunami are beyond the scope of PAGER. Tsunami alerts are issued by the National Oceanic and Atmospheric Administration (NOAA) Tsunami Warning Centers (http://tsunami.gov).

Four key datasets were developed for the calibration and validation of the three loss models: (1) PAGER-CAT (Allen and others, 2009), (2) a global ShakeMap Atlas (Allen and others, 2008), (3) Expo-CAT (Allen and others, in press) and (4) the previously mentioned PAGER global building inventory database. PAGER-CAT is a catalog of historical earthquakes with corresponding loss reports and triggered secondary effects.

PAGER-CAT combines several existing global catalogs in an effort to provide reliable information about each earthquake's source and its effect. It contains large earthquakes from 1900 to 2008 and is periodically updated. The complete PAGER-CAT includes up to 130 descriptors for each earthquake in a computer searchable format and will be available on the PAGER Web site. Additionally, a synopsis of the catalog is available in a community editable wiki (http://en.wikipedia.org/wiki/List_of_deadly_earthquakes_since_1900) that allows user additions and corrections.

The ShakeMap Atlas contains nearly 5,000 maps of estimated ground shaking from historical earthquakes since 1973 that are publically available on the Internet (http://earthquake.usgs.gov/eqcenter/shakemap/atlas.php). The generation of these maps required extending the ShakeMap methodology for application throughout the globe; enhancements include estimation of uncertainties (Wald and others, 2008b), global regionalization of ground-motion prediction equations, and global corrections for site-specific shaking amplitude based on topographic slope. When available, these maps are constrained by reported intensities, instrumental measurements of 
ground motion, and published earthquake rupture models. The Atlas provides the fundamental estimates of ground motion necessary to calibrate and verify PAGER's loss models.

EXPO-CAT combines information in the ShakeMap Atlas and PAGER-CAT to provide estimates of the number of people exposed to different levels of ground shaking for earthquakes since 1973. The information contained in EXPO-CAT is the key element for calibrating the empirical model and verifying the semi-empirical and analytical models. The catalog is freely available on the PAGER Web site and we encourage input from the seismologic and engineering community for its improvement.

An extensive effort has produced a country-specific global building inventory for use in PAGER loss calculations (Jaiswal and Wald, 2008). The database contains about 90 different building classes. For each country, the database specifies the fraction of the different building types, their functional use, and the average day and night occupancy. These data were compiled from a combination of numerous sources including United Nations statistics, national housing censuses, the World Housing Encyclopedia, and other published literature (Jaiswal and Wald, 2008).

\section{Summary}

After catastrophic earthquakes, it is difficult to rapidly assess the overall impact and the geographic extent of the disaster from first-hand accounts. Communications and physical access to the devastated areas are often disrupted resulting in a lack of reports from the most damaged regions. Additionally, effectively assimilating and assessing hundreds or thousands of individual reports is extremely challenging for local and national authorities during a crisis. PAGER provides a suite of products that, within minutes of an earthquake disaster, help emergency responders assess the geographic extent and potential impact of an earthquake, allowing for targeted reconnaissance and more efficient allocation of resources.

The Wenchuan, China, earthquake provides a specific example of how PAGER alert content aids earthquake response. For this earthquake, PAGER's exposure estimates provided a faster assessment of the overall situation than did the media. PAGER showed that the event was likely catastrophic within half an hour, and an accurate estimate of the geographic extent of the severe shaking was distributed within 15 hours.

PAGER's overall assessment preceded accurate fatality totals reported by major media outlets. Six hours after the earthquake, Reuters reported six fatalities. Five days later these number had increased to 29,000, still far short of the 69,000 killed and 18,000 missing and presumed dead reported a month after the earthquake by the United Nations Office for the Coordination of Humanitarian Affairs. PAGER results were widely distributed and used by major media outlets to show the area affected by the earthquake. Rather than just a point showing magnitude and epicenter, several of the media's schematic maps showed both intensity distribution and population exposure, achieving a significant communication goal of the PAGER project.

Many improvements to PAGER and its subsystems are underway that will improve PAGER's accuracy, timeliness, and content. PAGER's accuracy and timeliness will benefit from new methods to model the rupture extent and orientation. Additionally, modifications to ShakeMap will provide better estimates ground shaking. We foresee these changes enabling stable estimates of population exposure and shaking extent for large earthquakes within 2 hours their occurence. Improved content, including the potential triggering of landslides and liquifation and estimates of the number of people killed, injured, and displaced, will provide more actionable information to aid emergency response. 


\section{References Cited}

Allen, T.I., Marano, K.D., Earle, P.S., and Wald, D.J., 2009, PAGER-CAT-A composite earthquake catalog for calibrating global fatality models: Seismological Research Letters, v. 80, n. 1, p. 67-52.

Allen, T.I., Wald, D.J., Earle, P.S., Marano, K.D., Hotovec, Lin, K., and Hearne, M.G., in press, An atlas of ShakeMaps and population exposure catalog for earthquake loss modeling: Bulletin of Earthquake Engineering.

Allen, T.I., Wald, D.J., Hotovec, A.J., Lin, K., Earle, P.S., and Marano, K.D., 2008, An atlas of ShakeMaps for selected global earthquakes: U.S. Geological Survey Open-File Report 2008-1236, $47 \mathrm{p}$.

Bhaduri, B., Bright, E., Coleman, P., and Dobson, J., 2002, LandScan-Locating people is what matters: Geoinformatics, v. 5, p. 34-37.

Dewey, J.W, Reagor, B.G., Dengler, L., and Moly, K., 1995, Intensity distribution and isoseismal maps for the Northridge, Califoria earthquake of January, 17 1994: U.S. Geological Survey Open-File Report 95-92, 35 p.

Godt, J., Basak, S., Verdin, K., Wald, D., Earle, P., Harp, H., and Jobson, R., 2008, Rapid assessment of earthquake-induced landsliding, in Sassa, K., Proceedings of the First World Landslide Forum, Tokyo, 18-21 November 2008: The International Programme of Landslides, Global Promotion Committee, p. 219-222.

Jaiswal, K.S., and Wald, D.J., 2008, Creating a global building inventory for earthquake loss assessment and risk management: U.S. Geological Survey Open File Report 2008-1160, 109 p.

Jaiswal, K.S., Wald, D.J., and Hearne, M., in press, Estimating casualties for large worldwide earthquakes using an empirical approach: U.S. Geological Survey Open File Report.

Jaiswal, K.S., Wald, D.J., and Porter, K.A., 2008, Development of a global, semi-empirical approach for rapid estimation of human casualties due to earthquakes: Seismological Research Letters, v. 79, no. 2, p. 314.

Kircher, C.A., Seligson, H.A., Bouavid, J., and Morrow G.C., 2006, When the big one strikes againEstimated losses due to a repeat of the 1906 San Francisco earthquake: Earthquake Spectra, v. 22, p. S297-S339.

Lin, Y., and Chang, K., 2003, An improved capacity spectrum method for ATC-40: Earthquake Engineering and Structural Dynamics., v. 32, p. 2,013-2,025.

Marano, K.D., Wald, D.J., and Allen, T.I., in press, Global earthquake casualties due to secondary effects - a quantitative analysis for improving rapid loss analyses: Natural Hazards.

Peek-Asa, C., Kraus, J.F., Bourque, L.B., Vimalachandra, D., Yu, J., and Abrams, J., 1998, Fatal and hospitalized injuries resulting from the 1994 Northridge earthquake: International Journal of Epidemiology, v. 27, p. 459-465.

Porter, K.A., in press, Cracking an open safe-HAZUS vulnerability functions in terms of structureindependent spectral acceleration: Earthquake Sepectra.

Shakhramanian, M.A., Larionov, V.I., Nigmetov, G.M. and Sutschev, S.P., 2000, Assessment of the seismic risk and forecasting consequences of earthquakes while solving problems on population rescue (theory and practice): Ministry of Russian Civil Defense and Disaster Management Research Institute, $180 \mathrm{p}$.

Sipkin, S.A., Filson, J.R., Benz, H.M., Wald, D.J., and Earle, P.S., 2006, Advanced national seismic system delivers improved information: EOS Transactions, v. 87, p. 93-95.

Wald, D.J., and Allen, T.I., 2007, Topographic slope as a proxy for seismic site conditions and amplification: Bulletin Seismological Society of America, v. 97, no. 5, p. 1,379-1,395.

Wald, D. J., P. S. Earle, T. I. Allen, K. Jaiswal, K. Porter, and M. Hearne, 2008a, Development of the U.S. Geological Survey's PAGER system (Prompt Assessment of Global Earthquakes for Response), 
in World Conference on Earthquake Engineering, 14, Beijing, 12-17 October 2008: Chinese Association of Earthquake Engineering, International Association for Earthquake Engineering, Paper ID 10-0008, 8 p.

Wald, D.J., Lin, K., and Quitoriano, V., 2008b, Quantifying and qualifying ShakeMap uncertainty: U.S. Geological Survey Open-File Report 2008-1238, 27 p.

Wald, D.J., Quitoriano, V., Dengler, L., and Dewey, J.W., 1999a, Utilization of the Internet for Rapid Community Intensity Maps: Seismological Research Letters, v. 70, p. 680-697.

Wald, D.J., Quitoriano, V., Heaton, T.H., Kanamori, H., Scrivner, C.W., and Worden, B.C., 1999b, TriNet "ShakeMaps"- Rapid generation of peak ground-motion and intensity maps for earthquakes in southern California: Earthquake Spectra, v. 15, no. 3, p. 537-556.

Wald, D.J., Worden, B.C., Quitoriano, V., and Pankow, K.L., 2005, ShakeMap manual—Technical manual, user's guide, and software guide: U.S. Geological Survey Techniques and Methods, 132 p.

Wald, L.A., Wald, D.J., Schwarz, S., Presgrave, B.W., Earle, P.S., Martinez, E., and Oppenheimer, D., 2008, The USGS Earthquake Notification Service (ENS) - Customizable notifications of earthquakes around the globe: Seismological Research Letters, v. 79, no. 1, p. 103-110.

Wells, D.L., and Coppersmith, K.J., 1994, New empirical relationships among magnitude, rupture length, rupture width, rupture area, and surface displacement: Bulletin of Seismological Society of America, v. 84, p. 974-1002.

Wyss, M., 2004, Earthquake loss estimates in real time begin to assist rescue teams worldwide: EOS Transactions, v. 85, p. 3. 